\title{
DESAFIOS DA PESQUISA ATIVISTA EM EDUCAÇÃO
}

Andrea Brandão Lapa

Lucrezia Crescenzi Lanna Sabrina Severo da Silva $\left.{ }^{*}\right)$

\section{INTRODUÇÃO}

No Brasil, após alguns anos de governo de esquerda que trouxe grandes investimentos nas áreas sociais, vivenciamos o desmonte de direitos e conquistas coletivas. A implementação de uma cartilha neoliberal na educação resulta na desqualificação da escola pública e no enfraquecimento do papel do professor, o que cria uma série de dificuldades para a promoção da educação como direito de todos e em toda a sua plenitude de formação humana, tal qual reza a Constituição Federal: "visando ao pleno desenvolvimento da pessoa, seu preparo para o exercício da cidadania e sua qualificação para o trabalho" (BRASIL, 1988).

Defendemos uma concepção de educação como prática da liberdade, "o meio pelo qual homens e mulheres lidam de forma crítica com a realidade e descobrem como participar na transformação do seu mundo" (FREIRE, 2002, p. 15). A educação é, portanto, um campo especial para a emancipação social.

Daí chegamos ao um primeiro pressuposto: o da não neutralidade da educação. Não existe tal coisa como a transmissão de conhecimento objetivo, pois o conhecimento é uma representação particular da cultura dominante, selecionada por ênfases e exclusões, que servem a uma determinada agenda política (GIROUX, 1997). Justamente por ser um espaço de possibilidade da formação de sujeitos para a transformação social, a educação é atacada pelas políticas governamentais atuais, e ela se torna, mais uma vez, a grande trincheira da resistência.

\footnotetext{
${ }^{(*)}$ Andrea B. Lapa. Professora e vice-coordenadora do Programa de Pós-Graduação em Educação (PPGE) do Centro de Ciências da Educação da Universidade Federal de Santa Catarina PPGE/UFSC), linha Educação e Comunicação. Doutorado em Planejamento Urbano e Regional (2005) e pós-doutorado em Educação (2014) no Laboratório de Mídias Interativas da Universidade de Barcelona. Orcid: https://orcid.org/0000-0001-6073-4012
}

Lucrezia C. Lanna. Possui doutorado em Doutorado na Universidade de Barcelona - Universitat de Barcelona (2010). Profesora agregada en el Departamento de Comunicación y de Psicología, de la Facultad de Educación, Traducción y Ciencias Humanas de la Universidad de Vic ? Universidad Central de Catalunya. Desde el año 2007 es miembro del grupo consolidado Laboratorio de Medios Interactivos, especializado en el campo de la educación y de los medios de comunicación, un grupo interdisciplinar e inter-universitario entre la Universidad de Barcelona y la Universidad de Vic, que además integra investigadores de otras universidades catalanas. Orcid: https://orcid.org/0000-0003-2825-0477.

Sabrina S. Silva. Doutoranda na linha de pesquisa Educação e Comunicação (2017), Mestre na linha de pesquisa Educação e Movimentos Sociais (2010) ambos pelo Programa de Pós-Graduação em Educação da Universidade Federal de Santa Catarina. Graduada em Ciências Sociais na Universidade Federal de Santa Catarina (2004). Ordic: https://orcid.org/0000-0002-1806-2934. 
Soma-se a este cenário um papel cada vez mais presente das mídias nos acertos e descompassos sociais. Enquanto se acreditava na consolidação da promessa da internet como um espaço horizontal e mais democrático (PARISER, 2011), onde todos pudessem ser emissores além de receptores e onde a autocomunicação de massa poderia reequilibrar as relações de poder das sociedades (CASTELLS, 2013), as redes sociais mostraram-se como um espaço público vigiado, controlado e assustadoramente manipulado por seus algoritmos da inteligência artificial (SILVEIRA, 2017; ASSANGE, 2013). Mesmo quando cientes dos riscos, as pessoas aderem voluntariamente às novas estratégias de controle social e contribuem, assim, para a reprodução e reconfiguração do controle social e da indústria cultural nesse novo contexto da comunicação digital. Em uma estrutura que propicia a reflexão e a capacidade de indignação com os avanços negativos em áreas preciosas como os direitos humanos, as pessoas vão consolidando a segregação espacial da era digital, em bolhas ideológicas, no discurso de ódio nas redes digitais, na profusão de fake news, no marketing customizado da vida política do cidadão de qualquer nação (LAPA; PRETTO, 2019).

Na premência de uma educação ativista, isto é, aquela que vai, nesse contexto de retrocesso, ocupar e resistir garantindo a educação como o espaço da formação crítica dos sujeitos e da emancipação social, vale a pergunta sobre o papel da pesquisa em educação. Este artigo visa a problematizar aqueles que são postos por uma pesquisa comprometida com as demandas políticas da atual conjuntura brasileira. Põe na pauta da pesquisa em educação a reflexão das implicações trazidas por uma metodologia participativa de pesquisa-ação, enquanto apresenta uma proposta um desenho de pesquisa ativista e reflete sobre as tensões provocadas por sua implementação.

\section{CONTEXTO DA PESQUISA (AÇÃO)}

Fomos implicados a buscar uma metodologia ativista de pesquisa em educação a partir do projeto de pesquisa Conexão Escola-Mundo: espaços inovadores para formação cidadã, que tem apoio do CNPq e coordenação do prof. Nelson Pretto, da Universidade Federal da Bahia. O projeto alia ação e reflexão em uma proposta que investiga a experiência de um paradigma alternativo de educação aberta e conectada com o mundo pela inclusão crítica e criativa dos sujeitos na cultura digital. A hipótese é de que a perspectiva hacker ${ }^{1}$ pode vir a constituir um ecossistema favorável à

\footnotetext{
${ }^{1}$ É comum que se associe o hacker ao criminoso na internet, que rouba senhas, invade bancos e sistemas de segurança, mas estes seriam denominados crackers. Levy (1984) e Himanen (2002) delinearam um código de ética dos primeiros hackers, que são caracterizados como aqueles que têm participação ativa no seu grupo social, que produzem conteúdos e os fazem circular imediatamente para que possam ser testados e aperfeiçoados por todos em práticas de empoderamento, autoria e produção colaborativa.
} 
formação de cidadãos para os direitos humanos na cultura digital, a qual pode e deve ser incorporada às práticas pedagógicas nos contextos educativos formais e não formais, assim como estar contemplada na futura discussão da política pública brasileira em educação.

O projeto trata da criação de uma metodologia de intervenção nas escolas ${ }^{2}$, a ser construída com os professores em processos colaborativos. Parte do pressuposto de que a superação dos problemas históricos da educação começa de dentro da escola, do encontro e do comprometimento do seu coletivo na transformação de sua realidade em uma ação política que nasce e cresce nesta coletividade. A aposta é que uma pedagogia que propicie esta mudança pode ser criada para fomentar espaços de possibilidade no contexto da educação formal. O Projeto Conexão EscolaMundo visa, primeiramente, a criar e a experimentar metodologias transformadoras para a formação cidadã que estabeleçam na escola um novo paradigma, centrado em uma educação para a autoria, colaboração e produção, chamada de educação hacker, com vistas a apontar alternativas para professores nas escolas, orientações para a formação de professores e recomendações para políticas públicas (PRETTO et al., 2017).

A intervenção na escola é o campo de pesquisa para diversas pesquisas, com objetos distintos, como a própria metodologia da intervenção, as formas de comunicação, a integração de Tecnologias da Informação e Comunicação (TIC), o empoderamento de estudantes, a formação de professores, entre outros. A equipe de pesquisadores é composta por professores da universidade, estudantes da pós-graduação, da graduação e do ensino médio, além de professores da educação básica. Cada um, do seu lugar e da sua área de conhecimento (Humanas, Sociais, Exatas e da Terra, Biológicas), traz distintas abordagens para o problema em pesquisas singulares que se complementam na compreensão desta grande intervenção na escola.

De maneira resumida, a intervenção na escola segue o seguinte processo:

1. Integração universidade-escola. Aproximação entre o grupo de pesquisa e os professores da escola para a formação da comunidade de pesquisadores. Introdução às temáticas que envolvem a pesquisa, com a problematização no grupo das articulações entre direitos humanos e a integração das tecnologias na cultura digital.

\footnotetext{
${ }^{2} \mathrm{O}$ termo intervenção vem carregado de valores na área da Educação, associado ao autoritarismo e interferência externa. Contudo, reforçamos o caráter aplicado da pesquisa sobre a intervenção pedagógica, pois têm como finalidade contribuir para a solução de problemas práticos (DAMIANI et al, 2013). Vamos além, resgatando o sentido artístico do termo, que avança da contemplação e consumo das obras de arte para a participação e coautoria do público na consolidação de uma arte que se realiza em um processo de permanente devir e aproximação artista-público na vida cotidiana.
} 
2. Identificação de desafios do contexto educativo. Levantamento das demandas da escola, através de metodologias colaborativas (e.g. "fios soltos"). Criação de mapas conceituais para sistematizar os temas/problemas que foram identificados para cada contexto/turma.

3. Seleção e aprofundamento do problema educativo a ser trabalhado no ciclo. A partir da escolha de um desafio/problema da etapa anterior, detalhar e caracterizar o problema educativo través da metodologia denominada "árvore" (aplicada pelo Instituto de Desenvolvimento e Direitos Humanos/IDDH, parceiro do projeto), que descreve na copa e raízes possíveis efeitos e causas, respectivamente.

4. Criação coletiva de projetos de ação. Elaboração de propostas de intervenção por meio da técnica Table Top Analysis, que requer uma equipe para a solução coletiva de problemas - Método Task Analysis (KIRWAN; AINSWORTH, 2005). A metodologia consiste em uma equipe (em número equitativo e com representação de gênero) de pesquisadores da universidade, professores e estudantes da turma e da escola. Este coletivo parte da proposta inicial do plano de ação do professor, reflete sobre o papel das TIC como problema e como oportunidade para o enfrentamento da questão educativa escolhida, e cria conjuntamente um projeto de intervenção concreto.

5. Detalhamento do planejamento das ações educativas para a execução do projeto criado na etapa anterior.

6. Desenvolvimento das ações na sala de aula. Um momento que os integrantes do grupo de pesquisa e os professores da escola realizaram as ações planejadas nas etapas anteriores na escola.

7. Análise, avaliação e replanejamento. Após a execução do projeto, reflexão e análise da experiência pelo coletivo universidade-escola para iniciar novo ciclo de intervenção.

\section{PRINCÍPIOS TEÓRICO-METODOLÓGICOS}

Uma questão que se coloca a partir de um projeto deste caráter, de perspectiva ativista, é a necessidade de uma abordagem metodológica que tenha consonância com os princípios teóricosepistemológicos do projeto: de uma educação para a liberdade e a promoção dos direitos humanos, que integre as TIC por práticas democráticas, colaborativas e inclusivas. Este referencial traz algumas premissas importantes.

A primeira estaria na compreensão da responsabilidade do pesquisador como um intelectual transformador que se implica com seu contexto e procura evidenciar vozes dissonantes assumindo seu papel na transformação do mundo (SANTOS, 2014). Defendemos essa vertente 
política do trabalho do professor transformador (GIROUX, 1997) e do cientista, que julgamos consonante com outras falas mais recentes como a de Garry $\mathrm{Hall}^{3}$ e seu conceito de pesquisadores como intelectuais públicos e na de Nelson Pretto (2016) que defende os professores como ativistas comunicadores. Estes autores nos implicam a pensar no papel político da pesquisa, principalmente como reação ao lugar comum da pesquisa em educação, que segue ora fazendo um diagnóstico das ausências e demandas da escola e da formação de professores, ora elaborando e descrevendo fenômenos na/da escola de forma abstrata e pouco efetiva para seus profissionais e gestores. Garcia Canclini (2009) nos dá a dica: "trata-se, antes, de colocar-se nas interseções, nos lugares em que os sujeitos podem falar e atuar, transformar-se e ser transformados" (p. 208).

O comprometimento político do intelectual precisaria ser situado, no nosso caso, na América Latina e no Brasil. Esta seria mais uma premissa, de investir na valorização de uma Epistemologia do Sul, que reconhece a contribuição da ciência produzida em países centrais mas que se esforça por uma "antropofagia" para a superação da linha abissal que nos divide (SANTOS, 2007). Este posicionamento implica abandonar lugares tradicionais de pesquisa para a experiência prática que está normalmente à margem, em uma metodologia próxima da práxis, que não refuta a teoria mas se concentra na experiência viva e latente da ação prática. Para tanto, Garcia Canclini (2009) nos convoca a superar a adesão irrefletida assim como a resistência que procura apenas representar a voz dos silenciados, encarando de frente o desafio da ciência contemporânea: entender, nomear e estar nos lugares onde a vida é conflito e contradição. Estamos falando, portanto, dos espaços de integração das TIC na escola, que confluem, nos sujeitos, vida on-line e offline, mundo exterior e escola, estrutura linear e em rede, linguagem escrita e audiovisual, dentre tantas outras contradições que os tratamentos binários da relação TIC e escola colocam para os sujeitos na educação.

A quebra da distinção sujeito-objeto na pesquisa estaria no âmago de mais uma premissa. Uma vez que todo conhecimento é autoconhecimento e que a produção do conhecimento e seu produto são inseparáveis (Boaventura Santos, 1989), a pesquisa em educação feita na escola coloca em questão formulações convencionais de pesquisa científica que são, de fato, inviáveis nestas instituições devido à impossibilidade do afastamento do pesquisador e seu objeto. Contudo, defendemos o desenvolvimento de aproximações contextualizadas em perspectivas internas, apesar de tradicionalmente serem negligenciadas (à revelia de evidências como a auto-etnografia), pela suposição de que ser nativo é hostil à boa pesquisa e de que não há rigor metodológico suficiente para legitimar um conhecimento válido. A proximidade sujeito-objeto é benéfica para a pesquisa na

\footnotetext{
${ }^{3}$ Tema tratado na discussão do blog if: book ${ }^{\#}$, do Instituto para o Futuro do Livro, disponível em: $\underline{\text { http://futureofthe }}$ book.org/blog >. Acesso em 31 jul.2016.
} 
escola, pois o nativo tem uma compreensão sensível sobre o objeto, tem um olhar único porque é decorrente da posição que ocupa e das relações estabelecidas com os sujeitos com quem pesquisa (FREITAS et al., 2007).

Esta última premissa tangencia outra, a aproximação universidade-escola. Comumente, as pesquisas realizadas pelos professores da educação básica são desvalorizadas, enquanto se atribui outro status aos estudos conduzidos pelo intelectual da universidade sobre a prática do professor. Quebrar este afastamento começaria por dar preferência às formas de conhecimento mais inclusivas dos grupos sociais envolvidos na concepção, na execução e na fruição da intervenção e privilegiar a complementariedade ao invés da competição entre epistemologias. É o que Garcia Canclini (2009) nos cobra, quando diz que é preciso sair do lugar de conforto da pesquisa acadêmica na universidade (que prima por conceber os conhecimentos em abstrato) para nos colocar nas contradições e conflitos do chão da escola (o das práticas de conhecimento, o lugar da intervenção no mundo real). Para o Projeto Conexão Escola-Mundo, esta postura remeteria a valorizar a pesquisa feita no interior da escola com os próprios envolvidos.

Estas premissas anteriores falam do papel do professor da escola na pesquisa, que entendemos não haver outro que não o de professor-pesquisador. Vamos na esteira de Schön (1995) e seu conceito de professor reflexivo, Pedro Demo (1996) com o caráter formador da atividade de pesquisa, de Corina Geraldi e seu grupo (1998) no incentivo à pesquisa-ação entre professores. Isto é, seria importante dar condições, em tempo e espaço, para a participação do professor como pesquisador no Projeto Conexão Escola-Mundo. Essa valorização da participação ativa do professor também é importante pelo que Martín-Barbero (2009) chama de valorização das mediações históricas do comunicar, pois as transformações atravessam neste momento os mediadores socioculturais, que seriam tanto as figuras institucionais e tradicionais (escola, família, igreja, bairro) como também os novos atores e movimentos sociais emergentes (organizações ecológicas, de direitos humanos, movimentos étnicos e de gênero).

\section{MARCO METODOLÓGICO DO PROJETO}

Ao buscar uma coerência teórico-metodológica no Projeto Conexão Escola-Mundo, resgatamos um problema fundamental, que refere-se à forma como pesquisas podem resultar em políticas de ação e podem transformar a prática. Por este motivo, nos aproximamos de um paradigma emancipatório de pesquisa no qual a intenção não é meramente a de compreender fenômenos e situações, seja pela busca do padrão seja pela compreensão dos sentidos dados pelas 
pessoas, mas de transformá-los em prol da realização de uma sociedade baseada na equidade e na democracia para todos (COHEN; MANION; MORRISON, 2007).

A pesquisa segundo este paradigma envolve recapturar os sentidos das interações, reconstruindo as intenções dos atores envolvidos para compreender os fatos sociais em seus significados culturais, que são socialmente determinados. Ela está preocupada com a práxis, a ação que é informada pela reflexão com o objetivo da emancipação (KINCHELOE; MCLAREN, 2005). A pesquisa crítica em educação, portanto, tem uma intencionalidade prática e uma necessidade de desvelar qualquer exercício do poder que venha a limitar as liberdades, como as relações da escola com o mundo, o papel das escolas na diminuição das desigualdades, a construção social de conhecimento, produção e reprodução das relações de poder constituídas, por exemplo.

Como o intuito de suas metodologias são esclarecer, compreender e interpretar a comunicação dos sujeitos de ação e de fala (HABERMAS, 1984), a pesquisa-ação é uma opção bastante adotada por pesquisadores em exercício e professores nas escolas, porque, para eles, o contexto da prática (espacial, ideológico, histórico, social) é essencial. Carr e Kemmis (1986) e Grundy (1987) advogam que a pesquisa-ação é fortemente empoderadora e emancipatória porque dá aos práticos uma "voz", poder de decisão pela participação e controle sobre o ambiente e suas vidas profissionais (COHEN; MANION; MORRISON, 2007).

É correto afirmar que o termo pesquisa-ação descreve uma ampla gama de abordagens que integram teoria e prática com um objetivo de tratar importantes questões sociais enquanto elas são experimentadas. Tal metodologia centra-se na criação de áreas colaborativas para o desenho, promulgação e avaliação de ações libertadoras através da combinação de ação e reflexão em ciclos ininterruptos de produção coletiva de conhecimento. Por esta razão, para o escopo do Projeto Conexão Escola-Mundo, elegemos a pesquisa-ação como alternativa adequada e destacamos mais alguns princípios: autorreflexão e crítica através de diálogo, colaboração, aprendizagem e ação mútuas.

Aprofundamos, também, mais em questões que nos remetem à prática da pesquisa. Para nós, ela deve tratar, forçosamente, da colaboração participativa de pesquisadores treinados junto de comunidades locais, que produzem conhecimento diretamente relevante para a comunidade em questão, a qual é denominada de pesquisa-ação participativa (COHEN; MANION; MORRISON, 2007). Nosso objetivo principal coaduna com esta vertente, pois desenvolvemos uma pesquisa orientada para a transformação social, onde a contribuição para o campo de debate das ciências humanas e sociais é um resultado secundário. Ela carrega fortemente a noção de conscientização de 
Paulo Freire, que reforçou a ideia de que pessoas oprimidas podem, pelo diálogo, analisar criticamente sua situação e organizar ações para melhorá-la, podem se emancipar pela práxis. Também a práxis de pesquisa.

Para dar conta do empoderamento para a participação (seu princípio fundante), este modelo de pesquisa requer o engajamento ativo dos participantes em todos os aspectos do processo de pesquisa, do desenho à disseminação, que deveria evoluir de fases mais passivas de participação para outras mais interativas até finalmente a auto-mobilização ${ }^{4}$.Destacamos que a mudança acontece quando os sujeitos da pesquisa aprendem a usar novos conhecimentos para refletir sobre as suas próprias situações e, em seguida, participam sistematicamente e criticamente para superar desafios e dificuldades (COGHLAN; BRYDON-MILLER, 2014).

Algumas etapas do processo de pesquisa-ação participativa foram apontadas por Coghlan e Brydon-Miller (2014, p. 585):

1. questões que surgem do contexto - se o grupo não consegue articular claramente o problema, podem ser incorporados pesquisadores de fora para, através de processos participativos, ajudar a converter problemas nebulosos em tópicos coerentes e identificáveis para a investigação coletiva.

2. pesquisadores desenvolvem uma visão informada e crítica sobre o contexto real em que se situa o problema. O pesquisador funciona como um organizador da discussão, facilitador e recurso técnico: explica e alinha os propósitos, solicita e arranja contribuições individuais para a execução do projeto, articula agentes internos e externos, etc.

3. prática da auto-reflexão para evitar os perigos tanto da submissão entrincheirada de grupos desfavorecidos (ou vítimas de estruturas dominantes anteriores) quanto da persistência do pesquisador que não abre mão do seu papel de especialista e acaba impondo as suas próprias ideias.

Salientamos que o Projeto Conexão Escola-Mundo propõe a construção de projetos na escola, com o envolvimento ativo de professores e pesquisadores da universidade em práticas colaborativas de empoderamento para a transformação social. A pesquisa se dá com a participação de todos, do planejamento à execução, na ação e na reflexão, onde a experiência é promotora da

\footnotetext{
${ }^{4}$ Um baixo grau de participação é quando ela é apenas simbólica e os participantes em potencial são apenas informados sobre os objetivos da pesquisa, mas o projeto como tal ainda é desenhado, planejado e liderado pelos pesquisadores mais experientes. A participação real, aquela de poder partilhado, ocorre quando os processos de tomada de decisão são estruturados para incorporar a negociação entre participantes e os que estão no poder, com consenso como eventual objetivo. No estágio da auto-mobilização, os participantes têm plena soberania e responsabilidade para organização, execução e monitoramento da pesquisa inteira (COGHLAN; BRYDON-MILLER, 2014).
} 
produção de conhecimento a partir do diálogo na construção coletiva de sentidos coletivos acerca dos desafios e oportunidades dados à práticas de educação em direitos humanos através da apropriação crítica e criativa de TIC pela perspectiva hacker.

O campo de pesquisa é a intervenção que acontece na escola (duas escolas públicas no Brasil), onde vários professores e pesquisadores, de distintas áreas e objetos de investigação, estão envolvidos tanto na intervenção quanto na produção de dados para todo o grupo. Há distintas investigações sobre este campo de pesquisa comum, as quais espelham os princípios fundantes da pesquisa-ação e trazem, de maneira complementar, diferentes olhares para o Projeto Conexão Escola-Mundo. Apresentamos a seguir um desenho de pesquisa específico, criado para uma das 5 linhas de pesquisa dentro do Projeto, que trata da educação em direitos humanos na cultura digital, cujos objetivos são: a) identificar problemas e oportunidades da educação em direitos humanos com TIC pela ética hacker; b) descrever e identificar limites para a permanência e para a penetração da educação em direitos humanos com TIC na escola.

\section{UM DESENHO DE PESQUISA PARA A EDUCAÇÃO EM DIREITOS HUMANOS NA CULTURA DIGITAL}

O projeto está inserido dentro do paradigma participativo e da metodologia qualitativa de pesquisa-ação. A colaboração proativa de estudantes, professores e pesquisadores permitiu uma coleta de dados abrangente e diferenciada, que permitirá realizar uma triangulação metodológica (observação, entrevistas, questionários, análise do conteúdo de material gráfico e audiovisual), mas também uma triangulação de fontes. Vinte pesquisadores do Comunic (12 mulheres e oito homens) estiveram na produção de dados no Colégio Aplicação (a partir de agora CA) na Universidade Federal de Santa Catarina (UFSC) nos dois ciclos de intervenção: 2018 e 2019. Nos dois anos de pesquisa na escola estiveram envolvidos na intervenção um total de 15 professores, dos quais 10 atuaram, além da intervenção, como pesquisadores (nove mulheres e um homem), além de aproximadamente 420 alunos do 1o, 2o e 30 anos do Ensino Médio, e $4^{\circ}, 5^{\circ}$ e $7^{\circ}$ anos do Ensino Fundamental. No 10 ciclo de intervenção (fevereiro a dezembro /2018), foram realizados 20 encontros de planejamento com os professores e 31 intervenções nas salas de aula, enquanto que no 2o ciclo, que está em andamento (fevereiro a maio/2019), já foram realizadas nove reuniões de planejamento e 23 intervenções. Além desses momentos, houve um seminário de integração, um seminário de avaliação e um seminário de pesquisa, com todos os professores e pesquisadores. Duas estudantes do ensino médio colaboraram com a pesquisa e participaram de algumas reuniões, em especial o seminário de avaliação e as reuniões de planejamento de 2018. A Tabela 1 mostra os 
participantes da pesquisa, que foram selecionados por amostragem não probabilística por conveniência.

\begin{tabular}{|c|c|c|c|c|c|c|}
\hline & \multicolumn{3}{|l|}{2018} & \multicolumn{3}{|l|}{2019} \\
\hline & $\begin{array}{l}\text { Professores do } \\
\text { Colégio } \\
\text { Aplicação }\end{array}$ & $\begin{array}{l}\text { Pesquisadores } \\
\text { COMUNIC }\end{array}$ & Estudantes & $\begin{array}{l}\text { Professores do } \\
\text { Colégio } \\
\text { Aplicação }\end{array}$ & $\begin{array}{l}\text { Pesquisadores } \\
\text { COMUNIC }\end{array}$ & Estudantes \\
\hline Reuniões & 6 & 15 & 2 & 9 & 14 & 2 \\
\hline $\begin{array}{l}\text { Intervenções- } \\
\text { ações }\end{array}$ & 6 & 12 & $\begin{array}{l}180 \quad(60 \text { do } \\
\text { ensino médio, } \\
30 \text { do } 5^{\circ} \text { ano } 90 \\
\left.\text { do } 4^{\circ} \mathrm{s} \text { ano }\right)\end{array}$ & 7 & 11 & $\begin{array}{l}240 \quad(60 \text { do } \\
\text { ensino médio, } \\
90 \text { do } 5^{\circ} \text { ano, } 90 \\
\text { do } 7^{\circ} \text { ano) }\end{array}$ \\
\hline $\begin{array}{l}\text { Seminário } \\
\text { Integração }\end{array}$ & 7 & 20 & 420 & $\ldots$ & $\ldots$ & $\ldots$ \\
\hline $\begin{array}{l}\text { Seminário de } \\
\text { Pesquisa }\end{array}$ & & & & 9 & 20 & 2 \\
\hline $\begin{array}{l}\text { Seminário de } \\
\text { Avaliação }\end{array}$ & 7 & 20 & 2 & & & \\
\hline
\end{tabular}

Tabela 1 - Participantes da pesquisa.

Nas 29 reuniões de planejamento, de 2 horas e 30 minutos cada uma, aconteceram diversas atividades com os participantes (e.g. levantamento de demandas, elaboração de mapas conceituais de problemas da turma, seleção aprofundamento em um deles, criação de projetos por Task Analysis, detalhamento do planejamento, etc.) e a produção de dados em cada reunião incluiu a gravação de vídeos, materiais produzidos durante as dinâmicas colaborativas (e.g. mapas conceituais, árvores do problema, sínteses de debate, etc.). O mesmo se passou nos 2 Seminários de 6 horas cada (de Avaliação, para reflexão sobre a intervenção, e de Pesquisa, para a definição do projeto de investigação de cada um).

Nas 54 intervenções em sala de aula já realizadas se empregou o registro de observação com protocolo pré-definido por categorias como empoderamento, autoria, colaboração, protagonismo, participação, empatia, integração ao currículo, integração de TIC. Também foram coletados materiais produzidos durante a ação, como produções dos estudantes em diversos formatos (e.g. vídeos, mapas da empatia, relato de segredos em urnas, redações, etc.).

Além destes espaços de coleta de dados, foram realizados três questionários online semiestruturados, dois deles referem-se ao acompanhamento e avaliação do projeto geral em todas as escolas (diagnóstico pré-pós; espírito hacker) e um terceiro para acompanhar a formação do grupo durante o projeto. São eles: a) diagnóstico do projeto - sobre o perfil de imersão tecnológica e concepção de direitos humanos, aplicado a todos os professores e estudantes participantes do 
projeto, antes do início do projeto na sala/escola (março/18 e março/19); b) educação hacker para identificar o espírito hacker, dirigido a todos os participantes no projeto (professores e estudantes da escola e pesquisadores Comunic) após o 1o ciclo (dez/18 até abril/19); c) formação - para observar a reflexão sobre a ação dos professores e pesquisadores do Comunica após o 1o ciclo (março/2019).

\section{DEBATE}

A metodologia da pesquisa-ação participativa traz inúmeros desafios, que são vivenciados na prática da sua implementação. A partir dos primeiros resultados podemos já apontar algumas reflexões necessárias, das quais trazemos três: a) a co-criação da metodologia de ação; b) o desafio de integrar as TIC pela perspectiva hacker; c) os primeiros passos para a sustentabilidade.

Por ser uma metodologia de intervenção co-criada pelos envolvidos, requer maior flexibilidade dos pesquisadores, que vão escolhendo e/ou desenvolvendo métodos basicamente pelo seu potencial de desvelar conhecimento útil e incentivar o envolvimento das pessoas interessadas. Por este motivo Cohen e seu grupo orientam que os pesquisadores "tentam várias coletas de dados, métodos e instrumentos, desenvolvem métodos não convencionais e aplicam critérios não convencionais para determinar a adequação desses métodos" (COHEN; MANION; MORRISON, 2007, p. 585-586). Isto faz com que a pesquisa seja planejada como uma carta de navegação, em que as mudanças (tempestades, calmarias) vão determinar o ritmo e os caminhos. Como o processo torna-se mais importante que o produto, são justamente as escolhas feitas de modo coletivo e democrático ao longo do percurso que trazem a riqueza para a pesquisa e, portanto, não poderiam ser ignoradas. No 10 ciclo de intervenção pudemos observar um padrão de resposta, que se refere a uma frequente retomada do processo pelos próprios professores. Ao invés de uma trajetória linear e constante, havia sempre um movimento tipo onda, voltando uns passos atrás para depois seguir em frente com segurança, como uma prática de reflexão coletiva e formação de consensos. Por exemplo, a cada reunião de planejamento percebemos a necessidade das professoras trazerem novamente a problematização da reunião passada, demonstrando um amadurecimento provocado pela reflexão delas, individual ou coletiva, que aconteceu no período entre encontros, que necessitavam ser compartilhados e referendados coletivamente. Estes momentos foram sinais de que a parceria estava se consolidando, baseando-se em uma prática que estava condizente com a perspectiva hacker, de que não há problema em errar e rever pré-concepções (uma prática difícil para docentes), e também condizente com a educação em direitos humanos, pelo respeito aos tempos e demandas de cada um, que seriam negociados pelo diálogo respeitoso das diferenças. Este 
movimento dinâmico e orgânico foi a base da aproximação universidade-escola, o qual foi identificado pelas professoras como a importância da parceria entre pesquisadores do Comunic $e$ professoras do $C A$ nos espaços de avaliação do 1o ciclo (relatório, questionário de formação, questionário do espírito hacker).

A flexibilidade no tempo que o desafio anterior nos impingiu trouxe um outro desafio, que trata da integração de TIC pela perspectiva hacker. Como a perspectiva teórica-metodológica do Projeto Conexão Escola-Mundo requer que a proposta de uso de TIC venha, sempre, ancorada em um problema identificado e uma intencionalidade pedagógica definida, os pesquisadores do Comunic, receosos de nomear (no lugar dos professores) problemas e práticas para solucioná-los, demoraram para apresentar propostas de integração de TIC. Esta é uma fronteira extremamente delicada, onde um relacionamento horizontal significa empatia e parceria. Por conseguinte, e também pela premente demanda de educação em direitos humanos na escola, a maioria das intervenções, quando chegaram à fase de integração de TIC, restringiram-se à leitura crítica das mídias. Isto quer dizer que observamos nos planos de intervenção e na sua execução uma ênfase nas práticas que trataram das TIC como problema (e.g. analisar o discurso de ódio nas redes; identificar a reprodução da violência de gênero e de raça por influencers) enquanto que menos tempo foi dedicado ao desenvolvimento de práticas que tratassem das TIC como oportunidade (e.g. produzir conteúdos alternativos; promover o diálogo nas redes). Esta reflexão ao longo do processo nos conduziu a incluir na metodologia de intervenção espaços específicos para tratar coletivamente da integração de TIC nos quais os pesquisadores do Comunic estivessem "autorizados" a assumir o protagonismo de sua especialidade: problematizar usos críticos e criativos de TIC na perspectiva hacker. Destacamos dois momentos em especial: a Task Analysis e o Detalhamento de Projeto, os quais foram incluídos durante o processo como estratégia de fazer emergir o diálogo estruturado e propiciar a coleta de dados sobre um dos objetivos da pesquisa: a reflexão sobre os problemas e oportunidades das TIC na experiência de educação em direitos humanos. Pudemos observar como as TIC são culpabilizadas pelos problemas identificados acerca dos direitos humanos e como todos, professores e pesquisadores, titubeiam em experimentar alternativas criativas de uso de TIC, talvez duvidando de sua adequação para promover a autoria crítica e o protagonismo de crianças e jovens neste contexto da cultura digital. Tal reflexão orientou a ação do 2o ciclo, como, por exemplo, na ampliação de espaços de estudo e experimentação de uso de TIC pelos professores e pesquisadores. Um amadurecimento necessário acerca da apropriação crítica de mídias (como conteúdo e como prática), um passo necessário no letramento digital que antecede a liberdade criativa como autor e produtor da perspectiva hacker. 
Por fim, destacamos como resultados alguns primeiros passos que apontam a sustentabilidade do Projeto Conexão Escola-Mundo, que desdobramos em categorias como a permanência e a penetração na escola. Isto é, como o projeto caminha para a autogestão e os pesquisadores do Comunic tornam-se dispensáveis (a permanência), e como o Projeto Conexão Escola-Mundo contagia e se alastra pela escola, para além dos professores inicialmente envolvidos (a penetração). Trata-se da concepção de participação assumida, que não é apenas simbólica e é real (de poder partilhado), mas que almeja ir além, criando as bases para a auto-mobilização. Até o momento pudemos identificar já algumas ocorrências, inesperadas porque nossa hipótese inicial era de que seriam observáveis apenas após findo o projeto. A primeira a ser destacada seria na passagem entre ciclos/anos letivos, quando houve uma ampliação dos professores envolvidos e das turmas atendidas. Também observamos mudanças importantes em quatro professoras participantes em 2018 nas quais identificamos empoderamento e maior protagonismo. Por exemplo com a professora que no 1o ciclo teve uma intervenção em sua turma que contou muito com o apoio dos pesquisadores da universidade e que em 2019 se tornou vice-diretora e agora pensa em projetos de intervenção para toda a escola, considerando os pais e funcionários em ações de educação em direitos humanos com TIC. Ou a professora que no 2o ciclo está criando um projeto totalmente diferente do ano anterior porque aquele já está incorporado em sua prática (e currículo) e ela não precisa mais dos pesquisadores da universidade para realizar (recriando) aquela intervenção. E ainda aquela professora que já na 1a reunião de 2019 compartilhou conosco práticas de integração dos estudantes com TIC, inspiradas nas ações do ano anterior. Enfim, pudemos antecipar a pesquisa sobre a permanência e penetração identificando momentos de gatilho, para serem aprofundados futuramente com outros instrumentos no estudo de caso. 


\section{REFERÊNCIAS}

ASSANGE, Julian. Cypherpunks: liberdade e o futuro da internet. Tradução Cristina. Yamagami. São Paulo: Boitempo, 2013.

BRASIL. Constituição Federal de 1988. Promulgada em 5 de outubro de 1988. Disponível em: http://www.planalto. gov.br/ccivil_03/constituicao/constituicao.htm. Acesso em: 07/06/2019.

CARR, W.; KEMMIS, S. Becoming Critical. Lewes: Falmer, 1986.

CASTELLS, M. Redes de indignação e esperança: movimentos sociais na era da internet. Tradução MEDEIROS, C.A. 1. ed. Rio de Janeiro: Zahar, 2013.

COGHLAN, David; BRYDON-MILlER, Mary (Org.). The Sage Encyclopedia of Action Research. Londres: Sage Publications, 2014.

COHEN, L. MANION, L. MORRISON, K. Research Methods in Education. $6^{\text {th }}$ Edition. London/New York: Routledge, 2007.

DEMO, P. Educar pela pesquisa. São Paulo: Autores Associados, 1996.

FREIRE, Paulo. Pedagogia da autonomia: saberes necessários à prática educativa.22 ed. São Paulo: Paz e Terra, 2002

FREITAS, M.T. A pesquisa em educação: questões e desafios. Vertentes, n.29, p.28-37, jan./jun., 2007.

GARCÍA CANCLINI, N. Diferentes, desiguais e desconectados: mapas da interculturalidade. Rio de Janeiro: Editora UFRJ, 2009.

GERALDI, C.M.G.; DARIO, F.; PEREIRA, E.M. de A. (orgs.). Cartografias do trabalho docente. Campinas: Mercado das Letras, 1998.

GIROUX, H.A. Os professores como intelectuais. Porto Alegre: Artmed, 1997.

GRUNDY, S. Curriculum: Product or Praxis. Lewes: Falmer, 1987.

HABERMAS, J. The theory of communicative action: Vol. 1. Reason and the rational society. Boston, MA: Beacon Press, 1984.

HALL, G. Digitize This Book! The Politics of New Media, or Why We Need Open Access Now. Minneapolis: Minnesota University Press, 2008.

HIMANEN, P. et al. La ética del hacker y el espíritu de la era de la información. New York: Ediciones Destino, 2002.

KINCHELOE, J. L.; MCLAREN, P. (2005). Rethinking critical theory and qualitative research. In: DENZIN, N. ; LINCOLN, Y. (Eds.). The SAGE handbook of qualitative research. Thousand Oaks, CA: Sage, 2005, p. 303-342.

KIRWAN, B.; AINSWORTH, L. K. A guide to task analysis. London: Taylor \& Francis, 2005.

LAPA, A., PRETTO, N.L. (2019). La comunicación en disputa: el rol de educadores y científicos. REDU. Revista de Docencia Universitaria, vol. 17 , n. 1, 2019, p. 33-43.

LEVY, Steven. Hackers: heroes of the computer revolution. New York: Dell Publishing, 1984.

MARTÍN-BARBERO, J. Dos meios às mediações: comunicação, cultura e hegemonia. Rio de Janeiro: Editora UFRJ, 2009.

PARISER, E. "Tenha cuidado com os 'filtros-bolha' online”. TEDTalks, Youtube, mar. 2011. Disponível em http://www.ted. com/talks/eli_parisier_beware_online_filter_bubbles?language=pt-br\#t-71144 >. Acesso em: 30 out. 2017

PRETTO, N.D.L. Publicar ou perecer: desafios trazidos pelo digital. In: CARVALHO, M. V. C. DE; CARVALHÊDO, J. L. P.; ARAUJO, F. A. M. (Org.). Caminhos da Pós-Graduação em Educação no Nordeste do Brasil: Avaliação, Financiamento, Redes e Produção Científica. Teresina: EDUPI, 2016.

PRETTO, N. et al. Conexão Escola-Mundo: espaços inovadores para formação cidadã. Projeto de Pesquisa submetido ao CNPQ. UFBA, 2017.

SANTOS, B. S. Para além do Pensamento Abissal: Das linhas globais a uma ecologia de saberes. Revista Crítica de Ciências Sociais, 78, Outubro 2007: 3-46

Introdução a uma Ciência Pós-moderna. São Paulo: Graal, 1989.

SANTOS, E. Pesquisa-formação na cibercultura. Santo Tirso: Whitebooks, 2014.

SCHÖN, D. Formar professores reflexivos. In: NÓVOA, Antonio (Org). Os professores e sua formação. Lisboa: Dom Quixote, 1995, p.77-91.

SILVEIRA, S. A. Tudo sobre tod@s: redes digitais, privacidade e venda de dados pessoais. São Paulo: Edições Sesc São Paulo, 2017. 


\section{RESUMO}

O artigo tem um caráter teórico-metodológico e visa a contribuir com o campo da pesquisa em educação acerca de metodologias de pesquisa que podem resultar em políticas de ação e promover a transformação social. Apresenta um projeto de pesquisa sobre a educação em direitos humanos na cultura digital, que tem princípios como o papel do pesquisador como um intelectual transformador, a quebra da distinção sujeitoobjeto e a aproximação universidade-escola. Criou-se um desenho de pesquisa-ação participativa para investigar intervenções na escola básica para a educação em direitos humanos, sobre o qual são trazidos resultados preliminares para problematizar a pesquisa comprometida com a produção de conhecimento por meio da experiência coletiva de integração de mídias na perspectiva hacker.

Palavras-chave: Metodologia de pesquisa; ativismo; pesquisa-ação.

\section{THE CHALLENGES OF THE ACTIVIST RESEARCH IN EDUCATION}

\section{ABSTRACT}

The article has a theoretical-methodological approach that aims to contribute with the field of research in education about methodologies that can result in political action and transformation. A research project on human rights education in digital culture is presented, which has principles such as the role of the researcher as a transforming intellectual, the shrinkage of the subject-object distinction and the university-school approach. A participatory action research design was developed to investigate interventions in the basic school for human rights education, on which preliminary results are presented to problematize the research committed to the production of knowledge through a collective experience of media integration in a hacker perspective.

Keywords: Research methodology, activism, action research.

\section{LOS RETOS DE UNA INVESTIGACIÓN ACTIVISTA EN EDUCACIÓN}

\section{RESUMEN}

El artículo, de carácter teórico-metodológico, pretende contribuir al campo de la investigación en educación acerca de metodologías de investigación eficaces en políticas de acción promoviendo la transformación social. Se presenta un proyecto de investigación sobre la educación en derechos humanos en la cultura digital, que concibe el rol del investigador como un intelectual transformador, la ruptura de la distinción sujeto-objeto y la aproximación universidad-escuela. El proyecto de investigación-acción participativa estudia la educación en derechos humanos en la escuela básica. Resultados preliminares permiten problematizar la investigación comprometida con la producción de conocimiento a través de la experiencia colectiva de integración de medios en la perspectiva hacker.

Palabras clave: Metodología de investigación; activismo; investigación-acción. 